\title{
MAPEAMENTO PARTICIPATIVO: SUBSÍDIO À GESTÃO PARTICIPATIVA E AO MANEJO SUSTENTÁVEL DE RECURSOS NATURAIS DE COMUNIDADES TRADICIONAIS
}

\author{
Talita dos Santos Linhares ${ }^{1}$ \\ Luis Felipe Umbelino dos Santos ${ }^{2}$
}

\section{Resumo}

O presente artigo tem como objetivo principal apresentar uma revisão de mapeamento participativo, desenvolvido com o apoio de comunidades tradicionais para a gestão territorial e manejo de recursos naturais. $\mathrm{O}$ mapeamento participativo foi disseminado pelo mundo a partir da década de 1990, encontrando nas geotecnologias, ferramentas facilitadoras a sua propagação. Todavia, verifica-se que há alguns aspectos a serem superados, no que diz respeito a esse tipo de mapeamento. No Brasil, diversos trabalhos são desenvolvidos com o auxílio de comunidades tradicionais, principalmente, em territórios indígenas. Nestes trabalhos, verifica-se a importância do conhecimento científico associar-se ao conhecimento tradicional, visando a gestão da biodiversidade. Para tais constatações, realizou-se análise de bibliografia disponível sobre o assunto.

Palavras-chave: mapeamento participativo, comunidades tradicionais, gestão territorial, manejo de recursos naturais, geotecnologias.

\section{PARTICIPATORY MAPPING: SUBSIDY FOR PARTICIPATORY MANAGEMENT AND SUSTAINABLE MANAGEMENT OF NATURAL RESOURCES OF TRADITIONAL COMMUNITIES}

\begin{abstract}
This article aims to present a participatory mapping review, developed with the support of traditional communities for land management and natural resource management. Participatory mapping was disseminated around the world from the 1990s, finding in geotechnology, facilitating tools to spread. However, it turns out that there are some issues to be overcome, with respect to this type of mapping. In Brazil, several studies are developed with the aid of traditional communities, primarily in indigenous territories. In these works, there is the importance of scientific knowledge join traditional knowledge, aimed at biodiversity management. For these findings was held bibliography analysis available on the subject.
\end{abstract}

\footnotetext{
${ }^{1}$ Mestranda em Engenharia Ambiental pelo Instituto Federal de Educação, Ciência e Tecnologia Fluminense (IF-Fluminense). E-mail: talitalinhares4@hotmail.com.

${ }^{2}$ Professor do Programa de Mestrado Profissional em Engenharia Ambiental, do Programa de Pós-Graduação em Educação Ambiental e no curso de Licenciatura em Geografia do Instituto Federal de Educação, Ciência e Tecnologia Fluminense (IF-Fluminense). E-mail: 1fumbelino@gmail.com.
}

Sociedade e Território - Natal. Vol. 29, N. 1, p. 50 - 70.Jan./Jun. de 2017 
Keywords: participatory mapping, traditional communities, land management, natural resource management, geotechnology.

\section{MAPEO PARTICIPATIVA: GESTIÓN PARTICIPATIVA SUBSIDIO Y GESTIÓN SOSTENIBLE DE RECURSOS NATURALES DE LAS COMUNIDADES TRADICIONALES}

\section{RESUMEN}

Este artículo tiene como objetivo presentar una revisión de cartografía participativa, desarrollado con el apoyo de las comunidades tradicionales para la gestión de la tierra y los recursos naturales. La cartografía participativa se extendió por todo el mundo desde la década de 1990, encontrando en geotécnica, herramientas que facilitan su propagación. Sin embargo, resulta que hay algunos aspectos que hay que superar, con respecto a este tipo de mapeo. En Brasil, varios estudios se desarrollan con la ayuda de las comunidades tradicionales, sobre todo en los territorios indígenas. En estas obras, está la importancia del conocimiento tradicional asociado a los conocimientos científicos, con el objetivo de la gestión de la biodiversidad. Para tales hallazgos, se llevó a cabo el análisis de la bibliografía disponible sobre el tema.

Palabras clave: cartografía participativa, las comunidades tradicionales, de manejo del suelo, manejo de recursos naturales, geotecnología.

\section{INTRODUÇÃO}

O planejamento e gestão de áreas protegidas, muitas vezes é auxiliado pelo uso da geocartografia e os seus avanços teóricos-metodológicos, como a evolução das geotecnologias e do mapeamento participativo baseado na percepção ambiental. Estes avanços são relevantes para a melhoria dos instrumentos de gestão e do banco de dados e informações dos determinados locais, em virtude das percepções das populações tradicionais que são materializadas nos mapas, sendo elaboradas de forma coletiva (CAMPOS; MATTOS, 2011).

A elaboração de mapas pode variar, desde mapas desenhados, de forma livre, até aqueles construídos em folhas transparentes de acetato ou papel vegetal, sobre mapas elaborados a partir de imagens de satélite e informações vetoriais importantes, como delimitação territorial, rios, estradas, curvas de nível, entre outras (TRANCOSO et al., 2012). Atualmente, com a ajuda de instrumentos tecnológicos como imagens de satélites, cartas e mapas, o mapeamento participativo pode ser executado a partir de conhecimentos de um determinado grupo a respeito de seu ambiente vivido (SILVA, 2012). 
No que se refere à gestão das áreas protegidas, Chapin et al. (2005) indica que o mapeamento auxilia as comunidades a proteger o seu território e recursos naturais, fortalecer a organização política das comunidades e a criar planos econômicos e de manejo dos recursos naturais e documentação histórica para preservar a identidade cultural. Nesse contexto, tornase complexo planejar e ordenar, de forma correta, uma área sem que se tenha conhecimento da dinâmica das comunidades tradicionais, verificando áreas que ocupam e manejam, onde pescam, caçam, extraem recursos vegetais, cultivam e as técnicas utilizadas (ATAÍDE; MARTINS, 2005).

Em virtude dos avanços teóricos e metodológicos recentes nas áreas de geocartografia e antropologia e o reconhecimento do papel fundamental das comunidades tradicionais, tanto no ordenamento dos espaços protegidos dos seus territórios, quanto na gestão dos espaços territoriais especialmente protegidos buscou-se neste trabalho aprofundar a discussão acerca do uso do mapeamento participativo desenvolvido com o apoio de comunidades tradicionais como subsídio a gestão territorial e manejo dos recursos florestais buscando identificar as principais metodologias utilizadas no Brasil. Para elaboração do mesmo, foi realizada pesquisa bibliográfica em publicações, documentos técnicos e demais acervos bibliográficos.

\section{PERCEPÇÃO AMBIENTAL E MAPEAMENTO PARTICIPATIVO}

A percepção ambiental tem sido apontada pela Organização das Nações Unidas para a Educação, a Ciência e a Cultura (UNESCO) como um dos pontos primordiais para o planejamento ambiental. Sendo assim, a pesquisa em percepção ambiental vem sendo utilizada, no Brasil, por gestores e organizações relacionadas à administração de áreas naturais protegidas. Isso se deve ao fato da pesquisa, apresentar-se como uma ferramenta, que estimula a participação, das comunidades locais, nas decisões necessárias em Unidades de Conservação, assim como prevê a lei $\mathrm{n}^{\circ}$ 9.985/2000, que rege o Sistema Nacional de Unidades de Conservação (SNUC) (BARROS, 2012).

A percepção ambiental, de comunidades tradicionais, vem sendo utilizadas em muitas pesquisas. Essas comunidades tradicionais foram instituídas, por meio do Decreto 6.040 de 7 de fevereiro de 2017, a Política Nacional de Desenvolvimento Sustentável dos Povos e Comunidades Tradicionais (PNPCT) e foram criadas em um contexto de busca de reconhecimento e preservação de outras formas de organização social por parte do Estado. São denominadas comunidades tradicionais: 
grupos culturalmente diferenciados e que se reconhecem como tais, que possuem formas próprias de organização social, que ocupam e usam territórios e recursos naturais como condição para sua reprodução cultural, social, religiosa, ancestral e econômica, utilizando conhecimentos, inovações e práticas gerados e transmitidos pela tradição (BRASIL, 2007).

São consideradas comunidades tradicionais do Brasil, os povos indígenas, os quilombolas, as comunidades tradicionais de matriz africana ou de terreiro, os extrativistas, os ribeirinhos, os caboclos, os pescadores artesanais, os pomeranos, entre outros (BRASIL, 2007). A percepção ambiental de comunidades tradicionais é relevante, visto que estabelecem relações diretas com o meio ambiente. De acordo com Barros (2012), mesmo áreas que apresentem condições geográficas parecidas, cada sociedade se relaciona de forma distinta. Nesse contexto, a percepção ambiental, com influência dos aspectos culturais são relevantes na transformação do meio ambiente.

Uma das formas de percepção do ambiente é o mapeamento participativo, este processo é proveniente de um esforço coletivo que tem como intuito a valorização da percepção. Leva-se em consideração, o conhecimento de agentes locais no planejamento, conservação de recursos naturais, diagnóstico, ordenamento territorial e busca de resoluções de conflitos socioambientais (BARROS, 2012). Cada grupo social tem capacidade de elaborar proposições de ordenamento, a partir do momento, em que estas estejam de acordo com suas próprias concepções e sentimentos de território. Deve ocorrer, a participação de homens, mulheres, jovens, anciões, pensadores tradicionais e lideranças (BOTÍA, 2000).

Para Silva (2012), o mapa participativo é considerado uma ferramenta metodológica poderosa para melhoria dos instrumentos de gestão, assim como banco de dados e informações dos locais. Isso, em virtude, do entendimento das percepções das comunidades tradicionais presentes nos mapas, produzidos coletivamente. Dessa forma, a população que participa da elaboração dos mapas pode incorporar o sentimento de pertencimento nos momentos de decisões com seus conhecimentos sistematizados.

Deve-se destacar que, no que diz respeito à ciência ocidental, o mapa não deve ser visto como um instrumento neutro, mas sim como um portador de discurso (BAVARESCO, 2009). Segundo Lacoste (1997), os mapas apresentam um caráter dominador e de poder, visto que os mesmos são muito mais do que dados estatísticos ou conjunto de escritos. A carta é uma relevante forma de representação geográfica e é sobre esta, que informações devem ser colocadas visando a criação de táticas e estratégias. A representação do espaço, constitui-se 
uma forma de dominação essencial do espaço. A elaboração de uma carta requer um certo domínio político e matemático do espaço a ser representado, e configura-se como um instrumento de poder sobre o espaço e pessoas que nele vivem.

\section{MAPEAMENTO PARTICIPATIVO}

A elaboração de mapas de cunho participativo iniciou-se nas décadas de 1950 e 1960, no Canadá e no Alasca através do pioneirismo dos geógrafos que elaboravam mapas com o objetivo de lutar pelas terras dos povos nativos e indígenas canadenses, contribuindo para a negociação dos direitos indígenas. Nesse período, não há registros de outros mapeamentos de cunho participativo (CHAPIN et al., 2005).

Em 1980, surgiram um maior interesse por mapeamento participativo para diversas finalidades com a integração de geógrafos, antropólogos, povos indígenas, ambientalistas acerca de levantamentos ambientais, trabalhos de reconhecimento de terras indígenas, projetos de educação indígena com enfoque na gestão ambiental e territorial. Sendo assim, foram aliados métodos de pesquisa participativa e tecnologias como os SIG, os Global Position Systems (GPS) e o sensoriamento remoto para a elaboração de mapas, denominado mapeamento participativo. Contudo, geralmente, esses materiais são pouco divulgados devido a não publicação dos trabalhos, mas são importantes por apresentarem informações sobre subsistência, recursos naturais, dentre outros aspectos (CORREIA, 2007).

O mapeamento participativo foi disseminado pelo mundo a partir da década de 1990, encontrando nas novas tecnologias, principalmente as relacionadas ao Sistema de Informações Geográficas (SIG), uma ferramenta facilitadora a sua difusão. As pesquisas participativas atribuem importância igualitária entre conhecimento das populações locais e conhecimento dos pesquisadores. As pesquisas participativas podem utilizar-se da metodologia observação participativa e pesquisa participativas (HERLIHY; KNAPP, 2003).

No Brasil, o mapeamento participativo foi elaborado com diferentes grupos humanos, dentre os quais pode-se mencionar os povos indígenas, as comunidades quilombolas, os pequenos proprietários rurais e extrativistas, membros de associações e moradores urbanos visando a delimitação do território, a promoção e discussão do desenvolvimento local, a oferta de elementos que contribuam com planos de manejo e gestão em unidades de conservação e auxílio as políticas de etnozoneamento. Houve maior disseminação desses mapeamentos em 2003, embora esses projetos tenham tido início na década de 1990 (LIMA, 2010). 
Algumas são as terminologias empregadas para se referir a mapeamentos participativos realizados no mundo. Muitos deles se referem a metodologias iguais ou similares. Há diferença de acordo com a região na qual essas práticas são executadas. No Canadá e Alasca, por exemplo, onde surgiram os primeiros trabalhos, os termos mais comuns são "estudos dos usos da terra e conhecimento tradicional da terra", "estudos do uso tradicional da terra", "estudos do uso tradicional e da ocupação da terra", estudos do uso e ocupação da terra de aborígenes", mapas de subsistência", "mapas de subsistência e do uso de recursos" (CHAPIN et al., 2005).

No restante do mundo e, principalmente, em regiões de Terceiro Mundo são utilizadas as expressões "mapeamentos participativos", "mapeamento participativo do uso da terra", "mapas comunitários", "mapeamento de comunidades localizadas", "etnocartografia", "contra-mapeamento", “auto-demarcação", "delimitação de domínio ancestral” (CHAPIN et al., 2005).

Embora seja difícil o acesso aos mapas participativos, sabe-se da ocorrência dos mesmos na Ásia, como povos indígenas na Indonésia, Filipinas, China, Nepal, Tailândia, Camboja, Vietnã. Na Oceania, destacam-se trabalhos realizados na Austrália e Nova Zelândia. $\mathrm{Na}$ África, esses mapeamentos ocorreram no Quênia, Camarões, Gana, África do Sul, Congo, Tanzânia. Na América Central, pode-se mencionar países como Belize, Nicarágua, Honduras e Panamá. Na América do Norte, Estados Unidos, Canadá, Alasca. Na América do Sul, Suriname, Colômbia, Equador, Bolívia, Peru, Venezuela e Brasil (CHAPIN et al., 2005).

No Brasil, alguns mapeamentos participativos passaram a ser desenvolvidos a partir da década de 1990. Muitos deles promovidos por ONGs, em consonância a organizações indígenas. Sendo que, alguns desses mapeamentos também foram auxiliados por agências de cooperação internacional, instituições de pesquisa, governo federal ou estadual no país. No país, destacam-se os termos "levantamentos etnoecológicos", "mapeamento etno-ambiental dos povos indígenas", “mapeamento comunitário participativo", "etnomapeamento", “etnozoneamento", “macrozoneamento participativo", “diagnóstico etnoambiental”, "mapeamentos culturais", dentre outros (CORREIA, 2007).

Um outro termo utilizado por Acselrad (2008) e Herrera (2008) é a cartografia social. Essa para Herrera (2008) é utilizada para construir conhecimento de maneira coletiva, é uma abordagem da comunidade em relação ao seu espaço geográfico, histórico cultural, socioeconômico. A construção do conhecimento coletivo pode ocorrer a partir da elaboração 
de mapas e ao destacar os diferentes saberes que podem alcançar uma imagem coletiva do território. Nesse sentido, é possível a elaboração de mapas do presente, passado, futuro, assim como os mapas temáticos que permitem maior conhecimento do entorno.

Novas possibilidades surgem com a cartografia social, como por exemplo, mapas de conflito, mapas de redes, mapas de recursos. A partir deles pode se propor um instrumento a serviço da cidadania e a serviço de grupos relegados, visando observar os conflitos, expor situações injustas. Da mesma forma, que se pretende intervir, orientar os educadores sociais e profissionais comprometidos com a transformação social (HABEGGER; MANCILA, 2006). Nesse contexto, o mapeamento participativo surgiu nas últimas décadas como uma ferramenta de cunho popular para auxiliar a demarcação e defesa de territórios (SLETTO et al., 2013).

De acordo com Nelson e Wright (1996), o mapeamento participativo é o registro de conhecimentos advindos de um grupo específico em relação ao ambiente vivido, sendo colocado em prática com a ajuda de instrumentos tecnológicos como imagens de satélites, cartas e mapas. A busca por ações mais eficientes de conservação, pode ser realizada mediante a utilização do mapeamento participativo. Deve-se associar os conhecimentos locais das pessoas sobre seu espaço de vivência, informações relacionadas a complexidade dos ecossistemas, assim como incluir as necessidades locais nos projetos de gestão da biodiversidade.

Pimbert e Pretty (2000), destacam a importância do envolvimento comunitário na conservação e gestão da biodiversidade. Visto que, quando não há participação das comunidades, os custos operacionais de manejo e conservação são muito maiores. A produção de mapas pelas comunidades indígenas torna-se relevante, por serem utilizados na comunicação e solicitações de seus direitos. De acordo com Bavaresco (2009), os etnomapas, gerados com base nos conhecimentos das próprias comunidades, produz discussões a respeito de uma educação para gestão ambiental em sociedades indígenas.

Segundo Sletto et al. (2013), apesar do mapeamento ser utilizado, historicamente, como uma ferramenta própria das autoridades estaduais para propagar seu alcance e monitorar territórios e recursos, atualmente, um acesso difuso as ferramentas de mapeamento testa esse monopólio "direitos de utilização". Com a apropriação das tecnologias de mapeamento participativo, as comunidades ganham força para estabelecer novas relações com o Estado, reivindicando direitos sobre a terra e recursos que foram desconsiderados com o tempo. Nesse contexto, o uso de recursos naturais vem sendo diagnosticado com a utilização do 
mapeamento participativo. Por meio deste se determina as áreas de uso de uma comunidade tradicional e os recursos disponíveis, o que pode proporcionar um novo olhar para o conhecimento empírico e tradicional, inovações tecnológicas e o conhecimento acadêmico, estabelecendo ao pesquisador uma maior confiabilidade nos dados gerados e informações mais complexas em relação aos usos de cada recurso natural (BROWN et al., 1998).

Bavaresco (2009), vê os mapeamentos participativos como incentivador do debate dos problemas socioambientais vivenciados por povos indígenas, podendo ser utilizado também como um instrumento didático visando atividades de formação. Estas podem ter foco na gestão ambiental e idealização dos territórios pelas comunidades indígenas como ferramenta para auxiliar discussões relacionadas a ações de gestão, controle e fiscalização.

Para manutenção dos direitos sobre a terra e os recursos naturais é necessário mais do que um mapa. De acordo com Stocks (2003), algumas etapas devem ser respeitadas para interesses na sobrevivência cultural e no manejo de recursos sustentáveis. São considerados requisitos necessários a demarcação adequada da terra, estrutura política que possa negociar com o Estado, interesse comerciais e ONGs, possibilidade de negociar a exclusão de apropriações externas, aceitação das comunidades indígenas como manejadores legítimos e co-manejadores, assim como respostas, que atendam às necessidades financeiras, sem destruir recursos fundamentais e controle autônomo do território, acesso igualitário a educação e saúde.

Poole (1995), vincula o mapeamento participativo a cinco pontos, o reconhecimento dos direitos territoriais, bem como a demarcação dos territórios tradicionais, a proteção das terras demarcadas e conhecimento tradicional e manejo das terras tradicionais e dos recursos.

Atualmente, a utilização do Mapeamento Participativo em consonância as técnicas de SIG é de extrema importância para espacialização das práticas agroextrativistas comunitárias, podendo auxiliar ainda o delineamento do zoneamento da Unidade de Conservação. Com o uso do SIG, em Unidades de Conservação, por exemplo, com o mapeamento de uso dos recursos naturais, pode ser realizada a gestão da mesma, objetivando o planejamento de práticas futuras nas unidades (KOURY et al., 2010).

De acordo com Trancoso et al. (2012), há uma sequência de procedimentos para consolidação em SIG das iniciativas de etnomapeamento. Sendo que, os procedimentos são divididos em três fases, que se unem formando um ciclo. A primeira fase é o Sistema de Informação Geográfica - SIG, visando o planejamento do etnomapeamento com informações 
que deem suporte ao processo de mapeamento participativo. A segunda fase é o mapeamento participativo ou etnomapeamento onde os membros da comunidade colocam suas informações em papel vegetal/acetato ou na carta.

$\mathrm{Na}$ terceira fase denominada Sistema Etnográfico de Informação Geográfica EtnoSIG, há utilização das informações étnicas do mapeamento participativo fazendo uso de ferramentas de geoprocessamento. Contudo, de acordo com o autor, a maior parte dos trabalhos de etnomapeamento em comunidades indígenas se restringem a primeira e segunda fases. Destaca-se que a metodologia supracitada é voltada apenas a interface do etnomapeamento com o SIG (TRANCOSO et al., 2012).

\section{ALGUMAS LIMITAÇÕES DO MAPEAMENTO PARTICIPATIVO}

O mapeamento participativo é um método, que associa o conhecimento tradicional ao conhecimento científico. Desta forma, há sistematização de dados, informações a partir da ótica de grupos sociais, que muitas vezes, não tiveram oportunidade de expressar, de forma ampla, seus conhecimentos em relação as áreas que vivem, suas necessidades. De acordo com Koury et al. (2010), embora o mapeamento participativo seja relevante para o planejamento da gestão de áreas protegidas, por exemplo, os resultados obtidos do método merecem ser ponderados e deve-se ter cautela no momento de sua análise e utilização (KOURY et al., 2010).

Para Poole (1995), o mapeamento participativo é insuficiente para a garantia dos direitos territoriais e manejo dos recursos naturais. Uma outra observação crítica a respeito do mapeamento participativo é oriunda de Chapin et al. (2005), visto que para ele, muitos pesquisadores acreditam, que os mapas possibilitem compatibilidade entre pensamento tradicional e tecnologias ligadas ao espaço, atribuindo ao SIG a capacidade de arquivar e utilizar o conhecimento tradicional.

Outra crítica elaborada por Chapin et al. (2005), se refere a incompatibilidade entre os sistemas ocidentais para a elaboração e utilização de informações geográficas, com os sistemas aprimorados pelos povos indígenas. De acordo com os autores, o SIG configura-se como um instrumento de assimilação ligada a longas tentativas das sociedades ocidentais em destruir as culturas indígenas. Os autores ainda destacam, que o SIG é um sistema com domínio, principalmente, de técnicos que não são indígenas, além de ser difícil o manuseio e 
caro, o que pode dificultar a utilização da tecnologia por comunidades rurais. Os indígenas não estão envolvidos em todas as etapas dos mapeamentos participativos.

As pesquisas participativas aparecem com a não conformidade do caráter positivista, empregado nas pesquisas científicas que envolviam grupos humanos. Nesse contexto, buscase atribuir maior responsabilidade as comunidades, colocando-as no centro do processo de construção do conhecimento, descentralizando o poder do pesquisador. A participação das comunidades locais na pesquisa auxilia na conscientização e mobilização social (LIMA, 2010).

Devem também ser aperfeiçoadas, as metodologias participativas empregadas em pesquisas, no Brasil, pois apresentam sérias dificuldades, em virtude da precária estrutura social verificada em áreas rurais. Nesse caso, a capacitação é necessária o que eleva o custo e tempo da pesquisa, além dos resultados destas ainda continuarem sendo incertos (LIMA, 2010).

De acordo com Koury et al. (2010), a transferência do conhecimento tradicional para o mapa não é uma tarefa fácil e isso exige familiaridade dos moradores locais com as ferramentas de mapeamento participativo. O repasse do conhecimento tradicional para o mapa é uma tarefa difícil. Diante disso, caso seja utilizado o sensoriamento remoto para "ajustar" os dados, em decorrência do desconhecimento da comunidade em relação a técnica, pode haver alteração da informação.

Deve-se considerar também, que as metodologias do mapeamento participativo, necessitam de uma equidade conceitual, para facilitar o diálogo interinstitucional e a troca de experiências. Ou seja, deve-se eliminar divergências conceituais e uniformizar procedimentos (ATAÍDE, 2011). Considera-se também, que erros em relação a escala também podem ocorrer, já que os polígonos presentes em mapas elaborados por moradores tradicionais, na maioria das vezes, são maiores do que a realidade no campo, ao se tratar de determinado recurso natural (KOURY et al., 2010).

No Brasil, nos últimos anos, vêm se desenvolvendo alguns mapeamentos com a participação de populações tradicionais. Contudo, a utilização do SIG para o mapeamento do conhecimento tradicional ainda é precária, assim como seus resultados para criação de políticas públicas de uso da terra, criação e gestão de Terras Indígenas (TIs) e Unidades de Conservação (TRANCOSO et al., 2012). 


\section{A METODOLOGIA PARTICIPATIVA NA GESTÃO AMBIENTAL}

Segundo Diegues (2000) muitas das áreas habitadas por populações tradicionais conservam sua cobertura florestal e grande biodiversidade, em virtude do manejo que é característico do modo de vida dessas comunidades. O conhecimento tradicional demonstrado por essas populações são relevantes na relação entre homem e natureza e pode ser definido "como o saber e o saber-fazer, concebidos na sociedade não urbana/industrial e transmitidos oralmente de geração em geração". Os "saberes dos antigos", também conhecidos como conhecimentos tradicionais tem a transmissão oral como um dos pontos imprescindíveis para a sua propagação.

A metodologia participativa se destaca a partir do momento em que se estabelece um novo paradigma do desenvolvimento, baseado no desenvolvimento em bases sustentáveis. $\mathrm{O}$ processo atual, é de fortalecimento de distintas identidades socioculturais, presentes no Brasil, como por exemplo, os remanescentes de quilombos, e estímulo à participação popular nas instâncias deliberativas (SILVA, 2012).

Com intuito de evitar falhas e ineficiências no desenvolvimento de áreas com grande biodiversidade, chegou-se à conclusão, segundo Ataíde e Martins (2005), que as metodologias participativas são fundamentais para o planejamento e gestão territorial, visto que, deve-se associar conhecimentos científicos, tecnológicos, artísticos e culturais priorizando valores como o respeito aos seres humanos e aos recursos naturais.

Muitos autores acreditam, que em virtude do caráter estritamente tecnicista empregado na elaboração de planos de ordenamento territorial, vários deles não têm apresentado benefícios sociais esperados. Na concepção de Diegues (2000), ao atribuir aos cientistas a tarefa de elaborar planos e propostas, não levando em consideração a participação das comunidades, pode-se gerar propostas de ordenamento, não como ferramenta de desenvolvimento social, mas como gerador de conflitos e descontentamento (ATAÍDE e MARTINS, 2005).

O mapeamento participativo é muito utilizado na gestão de áreas protegidas. Para Ataíde e Martins (2005), por ser essencial no planejamento e gestão de áreas protegidas, a cartografia, por muitas vezes, esteve relacionada à conservação biológica. Com as novas geotecnologias, principalmente os SIGs, o planejamento e a gestão de áreas protegidas foram facilitados, devido a utilização de dados gráficos e descritivos. Portanto, quando as 
informações relacionadas ao ambiente são relevantes, a etnocartografia, pode ajudar a formulação de estratégias visando a conservação da diversidade biológica.

O uso de SIG é importante na gestão de territórios. De acordo com Trancoso et al. (2012), o etnomapeamento pode ser recurso que aponte locais com maior necessidade de recuperação ambiental, associando informações geográficas provenientes de diversas fontes com os conhecimentos indígenas.

Na concepção de Koury et al. (2010), nos dias atuais, o Mapeamento Participativo apresenta-se como uma importante ferramenta para subsidiar o planejamento de áreas, principalmente, as protegidas e ocupadas por populações tradicionais.

O estudo da etnocartografia, pode funcionar como um depósito de diversos conhecimentos que possibilita a melhor compreensão das relações entre de seus autores e o meio no qual vivem. Ao ser utilizada objetivando o planejamento, a etnocartografia permite a participação da população tradicional nos processos decisórios. Dessa forma, o saber tradicional vem sendo resgatado, visando o desenvolvimento sustentável. Não se deve restringir a participação dos povos tradicionais a elaboração dos etnomapas, mas sim incluílos no processo de tomada de decisões (ATAÍDE; MARTINS, 2005).

Pimbert e Pretty (2000), ressaltam a importância da interação comunitária nos processos de conservação no que diz respeito a gestão da biodiversidade, destacando que o não envolvimento das comunidades, pode ocasionar altos custos operacionais de manejo e conservação.

De acordo com Correia (2007), no Brasil os mapeamentos participativos têm propiciado debates e ações voltadas a gestão territorial em terras indígenas. Nesse contexto, instituições governamentais e não-governamentais obtêm importantes conhecimentos a respeito de territórios indígenas e seus usos. Baseado nesses conhecimentos, debates e ações ligadas a vigilância e supervisão do manejo sustentável, geração de renda possibilitadas pelas atividades sustentáveis estão sendo traçadas.

A presença de populações tradicionais em áreas de conservação de recursos naturais é algo relevante. De acordo com Brown (1998), no Brasil, principalmente na Amazônia, áreas destinadas à conservação dos recursos naturais, são ocupadas por populações indígenas, seringueiros e castanheiros. Estes, muitas das vezes, dependem e são responsáveis pela manutenção desses recursos e não devem ser retirados das áreas de conservação e dos processos de decisão que fazem parte de sua gestão. 
Nesse intento, a presença de comunidades na gestão de áreas protegidas é elemento relevante para a sustentabilidade, visando a conservação da biodiversidade e do patrimônio natural. Destaca-se, portanto, o potencial democrático e emancipatório mediante a participação de distintos atores sociais nos momentos de decisão (IRVING et al., 2006).

O modo de ver e as opiniões das comunidades locais se configuram como algo relevante no processo de gestão, contudo, o órgão gestor predomina na tomada de decisões. Elas são essenciais na proteção da biodiversidade e dos recursos naturais (SILVA, 2012).

\section{ALGUMAS EXPERIÊNCIAS DE MAPEAMENTO PARTICIPATIVO NO BRASIL}

Podem ser mencionados alguns importantes trabalhos de mapeamento participativo, no Brasil, buscando valorizar o conhecimento das comunidades locais acerca do espaço em que vivem. De acordo com Trancoso et al. (2012), no período de 2001 a 2003 foi desenvolvido o projeto Mapeamento Participativo das TIs (Terras Indígenas) Uaçá, Juminã e Galibi, no Amapá, pela Associação dos Povos Indígenas do Oiapoque em parceria com a ONG (Organização Não Governamental) The Nature Conservancy.

Em 2004 e 2005, foi realizado o Etnozoneamento Terra Indígena Mamoadate, localizada nos municípios de Assis Brasil e Sena Madureira, no Acre. Foi realizado de forma participativa com os povos indígenas Manchineri e Jaminawa. O etnozoneamento foi executado pela equipe Técnica da Secretaria de Meio Ambiente do Acre e consultores. Seu objetivo foi contribuir com o processo de autonomia destes povos respeitando a diversidade cultural. Houve elaboração e digitalização de mapa dos recursos hídricos para o Plano de Gestão Ambiental e Territorial da TI Mamoadate (FUNAI, 2006).

O trabalho "Etnomapeamento na Terra Indígena Poyanawa (Acre)", foi elaborado no ano de 2006, em parceria com a Organização dos Povos Indígenas do Rio Juruá (OPIRJ) e Associações de oito TIs. O projeto foi apoiado pela ONG The Nature Conservancy (TNC) e Fundação Gordon and Betty Moore. No trabalho mencionou-se o mapeamento do território, de acordo com diversos temas, localização de recursos. Para possibilitar a execução, foram realizadas oficinas de etnomapeamento, em todas as terras indígenas. Os etnomapas foram elaborados em folhas de acetato sobrepostas às imagens de satélite, nas quais foram utilizadas canetas retroprojetor 1.0mm e $2.0 \mathrm{~mm}$ de diversas cores (GAVAZZI, 2006).

A experiência citada em "O geoprocessamento na gestão ambiental em terras indígenas: uma experiência com etnomapeamento junto à comissão pró-índio do Acre", 
mostrou o desenvolvimento de materiais didáticos direcionados a população indígena do Acre. Para tal proposta, houve combinação de imagens de satélites, fotografias aéreas. Os etnomapas foram elaborados por professores e agentes agroflorestais, sob a coordenação da Comissão Pró-Índio, no ano de 2005. Eles retrataram a forma como as populações obtêm os recursos necessários, assim como apresentaram o valor de uso de cada recurso para as comunidades (CARVALHO, 2006).

O mapeamento apresentado em "Mapeamento participativo de riscos ambientais na Bacia Hidrográfica do Ribeirão das Anhumas Campinas, SP”, está inserido no contexto do projeto de políticas públicas apoiado pela Fundação de Amparo à Pesquisa do Estado de São Paulo (FAPESP) nº. 01/02952-1, intitulado "Recuperação ambiental, participação e poder público: uma experiência em Campinas". O Projeto tem a participação de equipe multidisciplinar, composta por profissionais e estudantes do Instituto de Geociências da UNICAMP, dos Institutos Agronômico de Campinas (IAC) e Florestal (IF), da Universidade de Brasília, da Universidade São Marcos e da Prefeitura Municipal de Campinas. Desenvolvido no ano de 2005, o mesmo passou por algumas etapas. A primeira delas foi a preparação e convocação dos participantes. A segunda delas foi a reunião de mapeamento de riscos. Nesta, foi transmitido conhecimento acerca da alfabetização geográfica/cartográfica e também a familiarização dos participantes com o ambiente do qual fazem parte. Foi feito o mapeamento de riscos propriamente dito. Cada risco é referenciado com canetas hidrocor. Houve exposição preliminar dos resultados alcançados por cada grupo de trabalho e reunião de mapeamento participativo para digitalização e tabulação dos resultados. Posteriormente, apresentou-se os resultados aos gestores daquela área (DAGNINO; CAPRI JR, 2006). 
A pesquisa "Mapa participativo inédito expõe os impactos do avanço da soja sobre a floresta", apresentou um outro mapeamento participativo, que foi realizado pelos comunitários de Santarém e Belterra, em parceria com o Sindicato dos Trabalhadores e Trabalhadoras Rurais de Santarém, em 2009. Esse, baseou-se em imagens de satélite e conhecimento tradicional de comunidades tradicionais da Amazônia. No mapa houve representação dos impactos da produção de soja na região oeste do Pará, identificando os pontos de desmatamento e problemas relacionados à expansão desordenada da soja na região. O projeto mapeou 121 comunidades locais, havendo a capacitação de mais de 50 lideranças de 28 diferentes comunidades no uso de GPS e interpretação de imagens (GREENPEACE, 2009).

No trabalho intitulado "A elaboração de documentos cartográficos sob a ótica do mapeamento participativo", buscou-se através do mapeamento, auxiliar o processo de regularização fundiária do território quilombola Castainho, localizado no município de Garanhuns-PE. Essa pesquisa foi desenvolvida, em 2007, no âmbito do Projeto de Infraestrutura Geoespacial Nacional - PIGN, coordenado pelo IBGE e University of New Brunswick - UNB. O procedimento metodológico dos envolvidos no processo foi a definição de grupos. Com as crianças, trabalhou-se croqui em sala de aula e croqui casa escola, para os adultos, houve educação cartográfica e mapa planimétrico (ANDRADE; CARNEIRO, 2009).

Outro mapeamento participativo denominado "Mapeamento Participativo do Uso dos Recursos Naturais da Floresta Estadual de Maués", realizado no Amazonas, pelo IDESAM Instituto de Conservação e Desenvolvimento Sustentável do Amazonas teve por objetivo caracterizar o presente uso dos recursos naturais realizado pela população residente e usuária da Floresta Estadual de Maués como ajuda a revisão de seu Plano de Gestão (KOURY et al., 2010).

Os procedimentos realizados no mapeamento participativo em destaque, foram a identificação do objetivo e temáticas do Mapeamento Participativo, posteriormente o planejamento das técnicas empregadas e elaboração de modo participativo de mapas e representações. Foram realizadas oficinas com os moradores locais. Os mapas confeccionados tiveram como base as imagens de satélite Landsat 5, que foram impressas em folha tamanho A0 $(841 \times 1189 \mathrm{~mm})$ na escala 1:120.000. Com o auxílio do papel vegetal sobre os mapas, houve possibilidade das comunidades locais destacarem áreas utilizadas para a exploração de 
recursos naturais, que eram marcadas no mapa para digitalização das informações. Para armazenamento dos dados, utilizou-se softwares de SIG's (KOURY et al. 2010).

No trabalho "Práticas de etnoconhecimento na gestão participativa do turismo sustentável na Amazônia: quilombo de tapagem (Oriximiná, PA, Brasil)”, buscou-se utilizar o etnomapeamento para ajudar à gestão participativa sustentável do turismo, em locais onde vive a população quilombola de tapagem, localizadas no Alto Rio Trombetas (Oriximiná, PA, Brasil). Esta comunidade apresenta seus territórios em áreas próximas, justapostas ou sobrepostas a algumas áreas protegidas na Amazônia. O procedimento metodológico foi a realização de pequenas oficinas com distintos grupos de comunitários para a elaboração do mapeamento participativo. Este utilizou imagem satélite LANDSAT 5 TM. Colocou-se uma folha transparente sobre a imagem georreferenciada no tamanho A3, para o mapeador espacializar na imagem de satélite o uso dos recursos naturais. Os resultados serviram para o desenvolvimento de planos futuros na região. A pesquisa foi realizada em 2008 (CAMPOS; MATTOS, 2011).

O mapeamento participativo indicado no texto "Mapeamento participativo e sua importância na identidade territorial de Barro Vermelho, Santo Amaro - Bahia”, foi realizado no povoado de Barro Vermelho, na Bahia, a partir do projeto de extensão universitária da Universidade Federal da Bahia (UFBA). Ele visou proporcionar aos habitantes das comunidades rurais, a espacialização da propriedade e o entendimento da sua identidade territorial. Os procedimentos metodológicos mencionados no texto, para colocar em prática o mapeamento, foi o levantamento bibliográfico no que diz respeito a cartografia participativa. A pesquisa foi desenvolvida entre os meses de maio e junho de 2011. Foi utilizada uma imagem satélite Spot 5 georreferenciada, com dados levantados no campo, com o uso do receptor GPS (Global Positioning System). Esse material possibilitou destacar dados, como a cobertura natural, edificações, campo de futebol, estradas e áreas de solo que encontravam-se expostos, observadas na imagem e posteriormente vetorizadas (ARAÚJO; NASCIMENTO, 2012).

Um dos trabalhos de mapeamento foi realizado, juntamente, com a Floresta nacional FLONA de Tefé- AM. De acordo com o trabalho intitulado “ Mapeamento participativo e uso do SIG: FLONA de Tefé-AM", o mapeamento desenvolvido no mesmo, teve o objetivo de analisar o uso da terra. A partir desta análise buscava-se, com auxílio de outros mapas, 
auxiliar o Plano de Manejo da Unidade de Conservação, citada anteriormente. As comunidades ribeirinhas auxiliaram a elaboração dos mapas (OLIVEIRA, et al., 2013).

No trabalho supracitado, foram desenvolvidos alguns procedimentos metodológicos, o primeiro deles foi o planejamento inicial, iniciado com reuniões com os gestores do ICMBIO/Tefé. Nestas reuniões foram decididos quais elementos seriam mapeados para a elaboração do Plano de manejo. Mapeamento este, baseado na cartografia Social/Participativa. Utilizou-se, inicialmente, imagens do Google Earth. O segundo procedimento realizado foi a atividade de campo, que visava a elaboração do mapeamento participativo com subgrupos da comunidade e pesquisadores. Nessa etapa, foi feita superposição de papel vegetal nas imagens de satélites, com o auxílio da comunidade. O terceiro procedimento metodológico é o uso do SIG. Houve sistematização dos dados de campo utilizando-se o software ARCGIS 10. Após os procedimentos destacados, houve avaliação e confirmação dos mapas temáticos gerados em computador a partir de apresentação para as comunidades ribeirinhas. Nessa ocasião, realizou-se discussão das zonas distintas a serem criadas para FLONA de Tefé. O zoneamento foi proposto pelos gestores do ICMBIO, Instituto Chico Mendes de Conservação da Biodiversidade, havendo delimitação de sua área mediante demanda dos comunitários (OLIVEIRA, et al., 2013).

Verificou-se, que o mapeamento participativo é elaborado e utilizado para diagnóstico de problemas ambientais, para a gestão territorial, identificação de áreas extrativas de recursos naturais e forma de manejo dos mesmos. A participação das comunidades tradicionais no processo de mapeamento, assim como a utilização das novas tecnologias, são agentes facilitadores da execução do mapeamento.

\section{CONSIDERAÇÕES FINAIS}

A percepção das comunidades tradicionais voltada a gestão ambiental, mostrou-se uma forte aliada no diagnóstico de carências, necessidades que podem nortear políticas públicas futuras associadas a essas comunidades e/ou áreas em que vivem. Durante da revisão bibliográfica, constatou-se a importância da cartografia de cunho participativo para o planejamento e gestão ambiental. Para alcance de tais resultados, vem sendo desenvolvidas no mundo, práticas de mapeamento participativo. Este, devido ao avanço das novas tecnologias, com destaque para os SIGs, facilitou a sistematização dos dados e visualização dos resultados obtidos para planejamento futuro e tomada de decisões. 
A metodologia participativa, analisada no artigo, foi o mapeamento participativo, que apresenta diferentes terminologias, dependendo da região do mundo, que o tema seja abordado. Foi destacado, que esta forma de mapeamento surgiu na década de 1960 e ao longo dos anos foi disseminada pelo mundo.

Desde o surgimento desta prática, as técnicas vêm se modernizando, com a utilização de softwares de SIG, imagens de satélite, mapas, cartas, que facilitam a sistematização e elaboração de mapas.

No Brasil, a propagação desses mapeamentos é recente e muito utilizados por comunidades tradicionais, principalmente pelas comunidades indígenas, sendo muitas vezes, usadas para a gestão de áreas protegidas. Alguns dos mapeamentos realizados no país, valorizando os conhecimentos tradicionais dos diferentes povos, foram mencionados no artigo, com a descrição de como eles foram executados e quais os resultados obtidos.

\section{REFERÊNCIAS}

ACSELRAD, H. (Org.). Cartografias sociais e território. Rio de Janeiro: IPPUR/UFRJ, 2008.

ANDRADE, E. D. V.; CARNEIRO. A. F. T. A elaboração de documentos cartográficos sob a ótica do mapeamento. Boletim de Ciências Geodésicas. Curitiba, v. 15, n. 3, p. 410-427, jul.set., 2009.

ARAÚJO, N. S.; NASCIMENTO, D. M. C. Mapeamento participativo e sua importância na identidade territorial da comunidade de Barro Vermelho, Santo Amaro - Bahia. Extensio, Florianópolis, SC, v. 9, p. 51-63, 2012.

ATAÍDE, M. S. A etnocartografia no Brasil - 10 anos depois. In: XXV Congresso Brasileiro de Cartografia, 2011, Curitiba - PR. Anais... Curitiba - PR, 2011.

ATAIDE, M. S.; MARTINS, A. L. U. A Etnocartografia como ferramenta de gestão. In: XXII Congresso Brasileiro de Cartografia e Simpósio De Geotecnologias para Petróleo, 2005, Macaé - RJ. Anais... Macaé-RJ, 2005.

BARROS, J. R.. A percepção ambiental dos quilombolas kalunga do engenho e do vão de almas acerca do clima e do uso da água . Ateliê Geográfico, Goiânia, GO, dez. 2012. Disponível em: <http://www.revistas.ufg.br/index.php/atelie/article/view/21980>. Acesso em: 15 jun. 2015.

BAVARESCO, A. A. O pjê e a Cartografia: Os mapeamentos participativos como ferramenta pedagógica no diálogo entre saberes ambientais. 2009. 128 f. Dissertação (Mestrado em Desenvolvimento Sustentável) - Centro de Desenvolvimento Sustentável, Universidade de Brasília, Brasília, 2009. 
BOTÍA, C. Z. Introducción. In: VIECO, J. J.; FRANKY, C. E.; ECHEVERRI, J. A.

Territorialidad Indígena y Ordenamiento em la Amazonia. Santafé de Bogotá:

Universidad Nacional de Colômbia, UNIBIBLOS, 2000. p.13-17.

BRASIL. Decreto Presidencial No . 6.040/2007, de 7 de fevereiro de 2007. Institui a Política Nacional de Desenvolvimento Sustentável dos Povos e comunidades Tradicionais em 25 de maio de 2007.

BROWN, I. F.; et al. Mapa como ferramenta para gerenciar recursos naturais: um guia passo-a-passo para populações tradicionais fazerem mapas usando imagens de satélite. Rio Branco: Brilhograf, 1998.

CAMPOS, L. G.; MATTOS, C. P. Práticas de etnoconhecimento na gestão participativa do turismo sustentável na Amazônia: Quilombo de Tapanagem (Oriximiná/PA, Brasil). Revista Brasileira de Pesquisa em Turismo. São Paulo, dez. 2011. Disponível em: <http://rbtur.org.br/rbtur/article/view/457/478>. Acesso em: 10 jun. 2015.

CARVALHO, A. L. A. O geoprocessamento na gestão ambiental em terras indígenas: uma experiência com etnomapeamento junto à comissão pró-índio do Acre. 2006. $127 \mathrm{f}$. Dissertação (Mestrado em Geografia Física)-Universidade de São Paulo, USP, São Paulo, 2006.

CHAPIN, M.; LAMB, Z.; THRELKELD, B. Mapping Indigenous Lands. Annu. Rev. Anthropol., 2005.

CORREIA, C. S. Etnozoneamento, etnomapeamento e diagnóstico etnoambiental:

Representações cartográficas e gestão ambiental em terras indígenas no estado do Acre. 2007. 420 f. Tese (Doutor Antropologia Social), Departamento de Antropologia - Dan, Universidade de Brasília, Brasília, 2007.

DAGNINO, R; CARPI JR, S. Mapeamento participativo de riscos ambientais na Bacia Hidrográfica do Ribeirão das Anhumas-Campinas, SP. In: III ENCONTRO DA ASSOCIAÇÃO NACIONAL DE PÓS-GRADUAÇÃO EM PESQUISA AMBIENTE E SOCIEDADE. Brasília-DF. Anais... Brasília-DF, 2006. Disponível em: <http:// www.anppas.org.br/encontro_anual/encontro3/arquivos/TA157-06032006-105325.PDF>. Acesso em: 12 mai. 2015.

DIEGUES, A. C. (Org.). Etnoconservação. Novos rumos para a proteção da natureza nos trópicos. São Paulo: Hucitec/Annablume/Nupaub, 2000. 290p.

FUNAI. Etnozoneamento Terra Indígena Mamoadate. Disponível em:

<http://cggamgati.funai.gov.br/index.php/experiencias-em-gestao/etnomapeamento-dospotiguara-da-paraiba-21/>. Acesso em 10 de jun. 2015.

GAVAZZI, R. A.; ALMEIDA, R. A. Etnocartografia, uma experiência com Mapeamento Participativo no Acre. In: II SIMPÓSIO INTERNACIONAL CAMINHOS DA CARTOGRAFIA NA GEOGRAFIA, 2., 2010, São Paulo. Anais... São Paulo: Departamento de Geografia - Fflch/USP, 2010. p. 223 - 233. 
GREENPEACE. Mapa participativo inédito expõe os impactos do avanço da soja sobre a floresta. Notícia - 15 - jan - 2009. Disponível em: <http://

www.greenpeace.org/brasil/pt/Noticias/mapa-participativo-inedito-exp/>. Acesso em: 12 mai. 2015.

HABERGER, S.; MANCILA, I. El poder de la Cartografia Social em las práticas contrhegemónicas o La Cartografia Social como estratégia para diagnosticar nuestro territori. 2006.

HERLIHY, P. H. Participatory Research Mapping of Indigenous Lands in Darién. Panama. Human Organization. Jornal of the Society for Applied Anthropology. P. 315-331, v. 62, n.4, Winter 2003.

HERRERA, J. Cartografía Social. 2008. Disponível em:

<www.juanherrera.files.wordpress.com/2008/01/cartografia-social.pdf>. Acesso em 10 de fev. 2015.

IRVING, M.; et al. (org.). Áreas protegidas e inclusão social: construindo novos significados. Rio de Janeiro: Fundação Bio-Rio/Núcleo de Produção Editorial Aquários, 2006.

KOURY, C. G.; FREITAS, C. C., CEZARE, C. H. G. Mapeamento Participativo do Uso dos Recursos Naturais da Floresta Estadual de Maués. Ed.: Instituto de Conservação e Desenvolvimento Sustentável do Amazonas - IDESAM, 2010. Disponível em: $<$ http://www.terrabrasilis.org.br/ecotecadigital/pdf/mapeamento-participativo-do-uso-dosrecursos-naturais-da-floresta-estadual-de-maues.pdf >. Acesso em $10 \mathrm{de} \mathrm{fev.} 2015$.

LACOSTE, Y. A geografia - isso serve, em primeiro lugar, para fazer a guerra. Papirus Editora, Campinas, SP, $4^{\text {a }}$ edição, 1997.

LIMA, L. P. N. S. Mapas Sociais: Propostas e Perspectivas. Brasília: EdUNB, 2010.

NELSON, N.; WRIGHT, S. Participation and power. In: NELSON, N.; WRIGHT, S. Power and participatory development. Theory and practice. Ed. Intermediate Tachnolgy Publications, 1995.

OLIVEIRA, M. G.; SUERTEGARAY, D. M. A.; PIRES, C. L. Z. Mapeamento participativo e uso do SIG: FLONA de Tefé-AM. In: XVI SIMPÓSIO BRASILEIRO DE SENSORIAMENTO REMOTO - SBSR, 2013, Foz do Iguaçu. Anais... Foz do Iguaçu : INPE, 2013.

PIMBERT, M.; PRETTY, J. N. Parques, Comunidades e Profissionais: Incluindo "Participação" no Manejo de Áreas Protegidas. In: DIEGUES, Antonio Carlos (org). Etnoconservação: novos rumos para a proteção da natureza nos trópicos. São Paulo Hucitec, 2000.

POOLE, P. Indigenous Peoples, Mapping and Biodiversity Conservation: Na Analysis of Current Activities and Opportunities for Applying Geomatics Technologies. BSP People and Forests Program Discussion Paper. Washington, D.C.: Biodiversity Support Program, 1995. 
SILVA, S. R. Comunidades Quilombolas e a política ambiental e territorial na Mata Atlântica. Geografia em questão, Paraná, 2012. Disponível em: <http://e-

revista.unioeste.br/index.php/geoemquestao/article/view/4967/4938>. Acesso em: 28 mar. 2015.

SLETTO, B.; BRYAN, J.; TORRADO, M.; HALE, Charles; B., Deborah. Territorialidad, mapeo participativo y política sobre los recursos naturales: la experiencia de América Latina. Cuadernos de geografia Revista Colombiana de Geografía, Bogotá, jul.-dez. 2013.

STOCKS, A. Mapping Dreams in Nicaragua's Bosawas Reserve. Human Organization. Journal of the Society for Applied Anthropology. Vol. 62, No. 4, Winter 2003.

TRANCOSO, R.; MILLER, R.; GOULART, A.; TRINDADE, H.; CORREIA, C. EtnoSIG: ferramentas para gestão territorial e ambiental de terras indígenas. In: PAESE, Adriana; UEZU, Alexandre; LORINI, Maria Lúcia; CUNHA, André (Orgs). Conservação da Biodiversidade com SIG. São Paulo, Oficina de Textos, 2012.

Recebido em Novembro de 2016

Aprovado em Junho de 2017

Publicado em Agosto de 2017 